\title{
The Making of Successful Female Family-Enterprise Leaders
}

\author{
Nadine Kammerlander (WHU - Otto Beisheim School of Management) \\ Elizabeth Bagger \\ Doris Sommavilla (Stonehage Fleming) \\ Sasha Lund (Core Values Consulting Limited)
}

KEYWORDS: Family Business, Women, Succession, female leadership.

When thinking about family business leadership, most of us will automatically envision a grey-haired, middleaged man. But in the $21^{\text {st }}$ century, a rising number of women - often daughters of these middle-aged men are entering the family firms and leading them in a particular, usually very successful, way.

These often highly accomplished women are rarely in the spotlight, so we know little about their journey as business successors. Not much has been written about their career paths, their decision to join the family business, and their unique experience.

To shed light on their fascinating paths and get a better understanding of female family leadership, we interviewed 46 female family business successors from 13 countries (i.e., Bolivia, Brazil, Colombia, France, Germany, Italy, Romania, Singapore, Spain, Sweden, Switzerland, UK, US.) Our insights were first published in Forbes Italia in July 2021. All women are in leading roles in prominent family businesses in diverse industries ranging from hospitality, food and beverages, wholesales and textiles to pharma, construction, steel, manufacturing and banking.

\section{Raising Female Leaders}

While interviewing, we quickly became aware that contrary to what the media may suggest - the upbringing of most female successors was very similar to their brothers, although women tended to pursue higher education and largely earned higher grades. In general, parents did not raise their daughters in a more protective environment than their sons, but in general expected more and better from them (perfectionism bias). If anything, some women stated that their parents were tougher with them to help them build a thicker skin: "My brother was the protected one. My dad asked me as a child: 'Do you want to learn how to swim? Go for it!' and then he threw me in the pool," said a successful American-Latina CEO.

Most young women (under the age of 45) spoke of not being raised differently because of their gender but rather because of other factors, such as character, priorities and interests. But these daughters felt no pressure to take over the family firm - somewhat unlike their brothers. So, the career paths of many female successors were often far from linear. Many interviewees spoke of having had no expectation or plans to one day lead the business. Instead, they first had successful careers outside the family firm. And in a number of cases, circumstances rather than their own planning led to them assuming a leadership role.

It became apparent that many next gen-female successors had to take matters in their own hands, although all of them had at least one parent in a leadership role in the business. But most female successors reported that their parents were very happy when they shared their plans of coming back to the family business and taking on a leadership role. "Getting one's hands dirty" and learning by doing have also drastically shaped their leadership style.

\section{Role Models: Grannies Rule}

As career paths were often complex and family firm leadership not planned, the question comes up: Who helps women on their way up? An entire network of people in the shadows have contributed to making success possible. Yes, many women paid professional coaches and mentors, as well as joined peer-to-peer networks to broaden their skill sets, work on their inner strengths and improve their ability to run the family business in a rounded way. However, we were surprised to see that many interviewees, especially in Italy and Germany, highlighted the importance of a very
Copyright ( 92021 The Authors. Entrepreneur \& Innovation Exchange is published at EIX.org. This is an open access article under the terms of the Creative Commons Attribution-NoDerivs License, which permits use and distribution in any medium, provided the original work is properly cited and no modifications or adaptations are made. View EIX.org Authorship Terms at https://eix.org/terms
FamilyBusiness 
specific family member - the grandmother - that blended with a competitive twist in the dynamic too.

Indeed, grandmothers seem to play a huge role in encouraging the female successors from an early age. A German successor told us: "My granny was my role model. I had a great granny... She was always the boss in the family... She told me that one must work hard to benefit from chance; I could learn a lot from her."

It was fascinating to observe the love, gratitude and respect many women showed when talking about their grandmothers. It became very clear that grandmothers often are the role model the next generation looks up to: resilient, positive and...never in the spotlight.

It seems that the daughters and grandmothers had one major experience in common: dealing with the person (her child or parent) who runs the business. They both understood the challenges that come with that, whether it is less family time or long working days. The grandmother could relate to the pains and struggles their granddaughters felt growing up, which allowed them to form a very strong and special bond. On average, grandmothers seemed more supportive and at times they sympathized more with the female next-gens than their mothers themselves. Together with the parents, grandmothers were also the ones who encouraged their granddaughters to pursue a solid education and gain experience outside of the family business first -- in order to earn credibility in front of senior family members and "deserve a role" in the family business.

\section{Parents: It's Complicated}

The relationship with parents revealed an interesting tapestry. In some cases daughters looked up to them (for instance, because they took the time to boost the daughter's education). The parents also acted as strong role models and were instrumental in building these women leaders' confidence: "In my annual review I was called 'a chip off the old block' which I was very happy with." In other cases, the relationship between the daughters and at least one parent (usually the business leader) was not always easy and was often portrayed through competition.

For instance, one German successor told us: "I have fought with my mother for 10 years. My mother liked to call me a gold-paid clerk, even when I did top management work." However, a majority of women said that their parents supported them and helped them to keep going even when they lacked poise. Many parents encouraged their daughters to learn by doing and failing: "My mom always encouraged me to try things I wanted and never to be scared of trying."

Not every mentoring model was positive, especially when parents had the tendency to go from one extreme to another. Too many compliments at times, and insults in case of mistakes, led to the opposite effect and created mixed feelings and loss of self-esteem. This dynamic emerged in at least two interviews. In these cases, coaching and structured mentoring helped our female leaders create a sounder self-image and led to them becoming the great leaders they are today. Having said that, the wounds are still there and are often seen as a great reminder of the difficulties these women had to go through.

\section{The Value of Outside Peer Groups}

Moreover, many women proactively reported on the support system of other women in similar situations. Joining not only professional networks but also peer-topeer groups and organizations helped them build confidence and realize that many more next-generation female leaders are in similar shoes. This has fostered a sense of belonging and created a safe space where different next-gens can share their experiences and learn coping strategies from one another. Learning from others and forgiving oneself for not being constantly perfect is also an important ingredient for success. This was particularly important for those female successors suffering from "perfectionism bias,"the belief that they are not allowed to make any mistakes in their private or professional life and that they need to successfully accomplish every task. For these women, repeatedly emphasizing their successes as well as talking about "failures" with friends and peers was an important step to overcome such bias, which could easily lead to a state of burn-out if not overcome timely.

In short, our research has shown that role models, including but not limited to female role models, played a key role in shaping these women's thinking and selfimage and that having a support system - both emotionally and practically - was imperative to their success.

\section{Supportive Spouses Help}

Spouses were also seen as a support system, rather 
than a role model. The women who are happily married emphasized the importance of a supportive spouse: someone who, for example, will care for the couple's kids. "I am running two ships: the business and the family. It would simply be impossible if I did not have such a supportive husband." It needs to be stressed that the divorce rate was high among the interviewees, suggesting that running a successful business and taking care of the family does not always go hand in hand and competitive behaviors within the couple could lead to family tensions.

All in all, most of the women spoke in appreciation of the senior generation and their achievements and said that they were proud of being part of legacy families where the senior generation supported them as much as they do.

\section{Challenges and Boosters to Leadership}

Many of the interviewees spoke of family dynamics leading to conflicts after having joined the family firm and being a challenging area for them to manage. In some instances, the business caused conflict and ongoing sibling rivalry long after the parents' passing. All the interviewees had a strong focus on the importance of the family getting along, but finding the balance between a healthy family life and running a successful business remains one of the main challenges, especially during a crisis. In fact, a few women said it was so difficult to manage both family life and business life that they left their careers.

Our respondents admitted that the family business gave them flexibility when they needed it for family reasons. However, the majority still felt burdened and stressed, since others expected them to manage both their business and private lives. "Family members are expected to arrive earlier and leave later. Employees have priorities regarding holidays and the phone is always ringing..."

Several women spoke of the challenge of gender, occurring with motherhood and how to spend their time. As stated earlier, having a support network and balance in the household is seen as vital. In general, "power struggles" with family members and male non-family managers can cause huge emotional rollercoasters in women, affecting both the family business and the family itself. When asked how these challenges can be dealt with, our respondents mentioned the power of their peer-to-peer networks and having an upbringing that gave self-confidence:

"My parents did not only talk about our family values, they lived by them. We were brought up knowing that both our parents were very hard-working. But they would always make time for the family. We had two sacred routines: Each week my parents would have a date night and on Sundays we would always have breakfast together as a family, no matter what, where we would discuss the week and my dad would tell us about the business and life in general. This shaped me and made me realize that it is possible to run a successful business while having a happy family."

All women agreed that is easier to speak about such challenges and their feelings to people outside of the family, such as with mentors and peer-to-peer networks. They feared that confiding in family members could lead to a specific issue resurfacing within family discussions later on and exacerbate the relationship among family members.

\section{Overcoming Stereotypes}

Fighting against prejudice and cliché remains a common daily struggle today. Many women said it was hard to gain respect from workers, customers, and suppliers. A German successor reported: "Our industry is male dominated. Sometimes customers request male sales agents; they refuse to talk to women. But my father doesn't want to fulfil those wishes. He always says: the business is led by a woman, we won't send a male sales agent, so take it or leave it."

In many cases, the female successors - in particular when they joined their family firm at a young age and fulfilled certain female clichés - had to prove themselves. This need for proving oneself has shaped personalities of female successors dramatically but has also led to respect among colleagues and customers. Several women pointed out that they had to learn "the hard way" to stay focused on the business and stop taking comments personally. Humor, flexibility and resilience helped them earn respect from senior family members, non-family managers, suppliers, customers and employees. For many, this was a painful process but has helped them in becoming more agile and building up resilience. In fact, creating and adapting a resilient mindset, coupled with curiosity and empathy, seems to be "the secret sauce" of successful female leadership. 
Another key success factor was taking the time to really understand the business: "I spent a lot of time speaking to other people to understand how and what they were doing, what they felt and what the thought process behind the actions was."

\section{Helpful Techniques}

The women we interviewed shared several tools and techniques that helped them overcome challenges. These seven stood out:

- Showing competence (e.g., by professional achievements before entering the family firm; by knowing every detail of the family firm; or through a lighthouse project in the family firm)

- Showing consistency (e.g., in HR-related decisions)

- Showing humor (e.g., in meetings characterised by role clichés)

- Leading with humility

- Being resilient by showing positivity during through challenging times and balancing excesses during positive times

- Showing strong and agile conflict-solving skills

- Being comfortable in admitting when outside help is needed (e.g., coaching for businessspecific challenges, family dynamics and their personal journey)

In the end, all women said they were proud that they were able to successfully overcome the reported challenges. But it took time: while some needed a few months to gain full respect, others reported years of proving themselves before they had gained the respect of family members and employees alike.

\section{Does Culture also Matter?}

We expected that the culture of a country would influence the way female leaders were raised and the amount and types of challenges they encounter. Interestingly, although grandmothers were often seen as strong role models (especially in Lombardia, where many women have founded and run family firms since World War II), these grandmothers still were products of the culture. Many of those interviewed women recall specific episodes in which their grandmothers justified the situation with sympathy by saying: "Leave all the hassle of running the family business to your (male) cousin/brother," revealing certain role clichés prevailing in the respective culture.
We observed a vast difference in how our interviewed female successors perceived their gender- and rolerelated challenges when taking on a leadership position in their family firm. While women from Nordic countries, Switzerland and North America hardly experienced such challenges, the successors from Italy, Germany, Bolivia, and Spain reported struggles to gain the respect of customers, employees, and consultants and to handle their parents in the business. Regarding the latter, they not only experienced power-struggles but also questions on lifestyle (e.g., on whether it is possible to run a business and at the same time be a mother) and the choice of their spouses (wealth, career > emotional support).

A majority of women interviewed from Mediterranean and Latin countries were discouraged from an early age from pursuing a significant role in the family business. Their male siblings, however, grew up with a sense of entitlement. Many female successors in those countries were encouraged by their parents to pursue higher education (often in accounting or finance at very prestigious universities) and land a high-status job strictly outside of the family business, ideally at a wellknown financial institution. In contrast, male siblings were educated in a more practical way and were groomed with the intention to bring them into the family business at some point.

\section{Female Leadership is Different}

Does female leadership differ from male leadership? Most of our interviewees had a clear answer: Yes!

It was fascinating to see that many women highlighted identical governance qualities and elements. Most importantly, all agreed that embracing ones' emotions is a positive aspect of leadership, as it adds a layer of understanding and depth. Leading with passion and compassion is encouraged and believed to create happier employees, leading to more productiveness for the organization. Coupled with empathy and a strong focus on communication, delegation, and participation, female leaders often see themselves as more diverse in their leadership style and approach as compared to their fathers, siblings, and family-external male managers.

By creating coherence in values and actions and by persistently ensuring that each and every employee understands and acts on those, a disciplined yet agile company structure can be formed. All women 
repeatedly talked about the importance of a holistic approach to leading their companies. They do this by embracing inclusion (i.e. caring for the specific needs and aims of all employees), and by encouraging participative instead of centralized decision making. For example, they regularly ask employees for their opinions and delegate some decisions.

While great time management is key to any successful leader, staying people-focused is a key source of pride for female leaders, and a large percentage stated that it was one of their main keys to success. Many female next-gens emphasized that such people-focused leadership style differentiated them from both their parents as well as hired male managers. Understanding the importance of each individual in the business, allowing next-gen family members to become acquainted with the different functions, and distributing tasks accordingly, leads to a well-oiled machine. Being focused, especially during difficult times, and being consistent in the decision-making process while staying collegiate, humble and grounded are also prominent skills of successful female leaders.

All in all, the 46 women we spoke with all agreed that their hard paths to success made them more disciplined and has helped them to embrace diversity (regarding gender, age, but also skills and attitude) and build successful teams. Being people-focused is an asset, not a weakness, and leads to employees trusting their management and subsequently performing better. Embracing the differences (of female and male family firm leaders, e.g., regarding their leadership) and hardships creates agility and leads to resilience - a skill that is considered to be one of the most essential skills to have today. By being resilient, humble and agile, women not only lead successful family enterprises but also help form the empires of tomorrow.

\section{The Takeaway}

Here are some key take-aways for future female leaders:

- Find your own role in the family business. There are many potential ways how you can contribute to the family business, yet you need to articulate your plans and follow your dreams.

- Aim to find your own way. Aligning your heart and your mind when taking on a leadership role and making decisions is a good start.

- Don't keep your experience, your successes, and your failures to yourself. Talk about them in order to serve as a role model for the next generation. 